\title{
LA REFORMA DEL ESTADO DE BIENESTAR: DERECHOS, DEBERES E IGUALDAD DE OPORTUNIDADES*
}

\section{Ricardo Montoro Romero}

Universidad de Valladolid

\begin{abstract}
RESUMEN
Partiendo de la situación de crisis del Estado de Bienestar y basándose en los postulados defendidos por la óptica del Welfare mix, en este artículo se examinan la situación de derechos y deberes propia del Estado de Bienestar, la necesidad de vincular la política social con la política económica, los límites entre la privacidad y la publicidad, y la estrecha vinculación entre bienestar individual y bienestar público. En este marco, se formulan sugerencias de reforma del Estado de Bienestar hacia el modelo de Sociedad del Bienestar rescatando el principio individualista y redefiniendo la igualdad de oportunidades en un escenario en el que Estado, mercado y familias concitan sus esfuerzos para lograr el Bienestar social e individual en una nueva fase histórica que sigue a la del Estado de Bienestar.
\end{abstract}

\section{PRESENTACION}

El Estado de Bienestar toca a su fin. ¿Desaparecerá con él la idea de Bienestar? ¿Qué modelo de sociedad le seguirá? ¿La transición será convulsiva o, al contrario, lenta y equilibrada? ¿Qué cambiará y qué permanecerá en la nueva evolución? Este artículo pretende dar respuesta a estas preguntas partiendo de la actual crisis del modelo de Estado de Bienestar y defendiendo la idea genéri-

* Este artículo forma parte de los resultados de un proyecto financiado por la Comisión Interministerial de Ciencia y Tecnología, Plan Nacional de I + D. 
ca de Bienestar por diversas razones fundamentales de armonía y equilibrio social. En esta revisión, deberán tenerse en cuenta ciertas cuestiones importantes como son el contenido del modelo mixto de Bienestar (Welfare mix), el contenido de las demandas sociales que alimentaron hasta ahora el modelo de Estado de Bienestar y entendidas ahora en clave de derechos y deberes, y, finalmente, el papel que juega la igualdad de oportunidades en el terreno de una sociedad desigualitaria pero estimulante para las individualidades. En las siguientes páginas intentaremos analizar todas aquellas cuestiones entendiendo que el acceso desde el Estado de Bienestar en su fase más crítica al modelo de Sociedad del Bienestar, basada en el Welfare mix, implica volver a reflexionar sobre ciertos supuestos básicos que afectan a colectividades tanto como a individualidades. En una sencilla frase, el paso de un modelo a otro implica el paso de concebir las ayudas e impulsos vinculados al Welfare como un modo de vida a entenderlos como una nueva oportunidad.

En primer lugar, intentaremos aclarar la diferencia que existe entre Estado de Bienestar y Bienestar, defendiendo la tesis de que el modelo del Estado de Bienestar implica una apropiación excesiva de la figura del Bienestar, mucho más amplia y rica. A continuación, examinaremos algunas de las principales transformaciones del Bienestar que pueden preverse en el modelo social que deberá seguir en el tiempo al definido por el Estado de Bienestar. A tal efecto, haremos especial hincapié en las áreas específicas de implantación del Bienestar, en la necesaria conexión de la política social con la política económica, en la generación de una nueva esfera pública, y en la coincidencia entre bienestar colectivo y bienestar individual. Este marco nos permitirá adentrarnos en el examen de los derechos y deberes implícitos en la demanda de servicios que caracteriza a cualquier figura del Bienestar. Y, a continuación, veremos el papel que juegan los tres principales agentes vinculados al Bienestar (Estado, mercado y familia). Después de exponer las limitaciones de cierta lectura moderna del pluralismo del Bienestar, terminaremos situando el problema de la igualdad de oportunidades vinculado a la discriminación positiva sobre unas nuevas bases.

\section{BIENESTAR Y ESTADO DE BIENESTAR: UNA LOGRADA CONFUSION}

El término Estado de Bienestar se ha hecho tan familiar, tan, incluso, popular, que ha absorbido por completo toda la idea de Bienestar. Como ha escrito de forma muy clara Richard Rose: «El Estado de Bienestar es ya una expresión familiar, lo que no impide que sea confusa. La familiaridad del término refleja el reconocimiento de que el Estado desempeña un papel fundamental en la provisión de los principales bienes de Bienestar que pueda desear una sociedad moderna, como ocurre con la salud, la educación, y la seguridad en obtener una renta cuando se es viejo o se está enfermo. Pero es una expresión confusa porque 
reduce el Bienestar exclusivamente a las acciones del Gobierno. Puede admitirse que el papel del Estado en la producción del Bienestar sea importante, pero el Estado no tiene el monopolio de la producción del Bienestar» (Rose y Shiratori, 1986: 13). La confusión sembrada por la unión de Estado y Bienestar no sólo se encuentra de esta manera en la inmensa mayoría de la literatura especializada, sino que ha pasado a ser utilizada por la población en general como una expresión obvia en el sentido de que, relacionado con el Bienestar, sólo cabe la existencia del Estado de Bienestar. Las palabras pueden engañar, y, como sugiere Rose, cuando no existen definiciones claras y concretas, los debates son más bien inútiles (Rose, 1984: i). Aquí, Estado quiere significar institución estatal y no situación o posición. De cualquier forma, se trata de una confusión terminológica que conviene aclarar si queremos plantear el modelo de Sociedad del Bienestar.

Como decíamos, el término Estado de Bienestar es confuso y engañoso porque es reduccionista: limita la existencia del Bienestar a la única acción del Gobierno o del Estado, de manera que no existe Bienestar fuera de esa acción o intervención (cfr. Rose y Shiratori, 1986: 13 y ss.). La asociación Estado y Bienestar tiene una clara legitimidad histórica, es cierto. Así nació, sobre todo a partir del Informe Beveridge. Pero esto no impide señalar lo inapropiado de la absorción de un término por otro; lo inapropiado de suponer que no hay Bienestar sin Estado ni Estado sin Bienestar. La primera de las correlaciones es atribuible a cualquier forma de Estado de Bienestar; la segunda, a los Estados modernos occidentales, especialmente los Estados europeos. No es correcto pensar, como hace el socialismo reformista, que, en la situación de Estado de Bienestar, el Estado organiza algo que le es de alguna forma ajeno y que se denomina bienestar. Lo que ocurre más bien es que el término bienestar cualifica o adjetiva al Estado moderno. Es decir, el moderno Estado es definido en buena parte por la intervención que supone la figura de Estado de Bienestar (Giddens, 1994: 134). Lo que ha ocurrido es que cuestiones características del Bienestar, como pueden ser la pobreza, el desempleo, la educación o la salud, no surgieron como tales de forma socialmente espontánea, de manera que el Estado se las encontró en su camino y decidió actuar sobre ellas. Formaron parte constituyente del mismo proceso de formación del Estado moderno y, en definitiva, del Estado de Bienestar. Aquellas cuestiones, evidentemente, eran el resultado de los conflictos existentes entre agencias estatales y otras organizaciones y grupos. Pero no se puede decir, en sentido estricto, que, por ejemplo, el pauperismo fuese una condición de individuos aislados que vivían en la sociedad civil, sino que se conformó en y a través de la intervención estatal. De alguna forma, el Estado crea la situación de pauperismo (sobre bases materiales, ciertamente, pero sin configuración social ni política). Con otras palabras, el Estado no encontró enfrente a la sociedad civil y decidió actuar sobre ella, sino que la subsumió en buena parte en su mismo proceso de conformación (Giddens, 1994: 134-135). En este largo proceso, el Estado se ha apropiado del Bienestar hasta hacerlo consustancial a sí mismo, hasta impedir ver la posibilidad de Bienestar sin la presencia (total o parcial) del Estado. 
Afortunadamente, cada vez son más numerosos los analistas que intentan demostrar que el surgimiento del Estado de Bienestar se ha producido de la manera que nosotros señalamos: no como resultado de una conspiración capitalista para poner coto a las clases trabajadoras organizadas (Swann, 1988: 9), sino más bien siguiendo las pautas marcadas por ambiciosos políticos y visionarios reformistas que se basaban en una vaga idea de orden y consenso sociales (Ashford, 1986: 4). En todo esto, no debemos olvidar, como señala Giddens (1994: 136), que los elementos básicos del Estado de Bienestar se asentaron en la mayoría de los países occidentales bastante antes de la Segunda Guerra Mundial, bajo gobiernos conservadores. Y que algunas de sus piezas clave surgieron a raíz de las masivas necesidades planteadas por la Primera Gran Guerra (1914-1918) y ratificadas más tarde por las penurias vividas en la Segunda (1939-1945). Algunos modernos revisionistas del Estado de Bienestar pretenden interpretar que las instituciones del Estado de Bienestar se asentaron definitivamente para hacer frente a la masiva incertidumbre en que vivía la población europea al acabar las dos guerras mundiales (Goodin y Legrand, 1987), en línea con lo señalado hace bastante más tiempo por Peacock y Wiseman (1961). Estas explicaciones fundamentan bastante bien la idea de que el Estado de Bienestar no surgió precisamente en épocas de serenidad y de negociación, sino en momentos de profunda crisis, cuando la sociedad civil había dejado de existir y la población carecía de medios materiales de subsistencia; momentos especialmente adecuados para que esa población prestase oídos a los fáciles consejos unificadores de los defensores de la única institución total capaz de responder con rapidez y eficacia: el Estado. Cuando reflexionamos desde un mundo de abundancia, civilización y paz conviene recordar que el Estado de Bienestar surgió sobre las cenizas de masivas destrucciones asumiendo tareas que era imposible que nadie realizase con propiedad. La pregunta que debemos hacernos es qué papel juega en un mundo como el nuestro, donde las fuerzas de generación de orden y de riqueza pueblan una sociedad civil estructurada con una máxima complejidad.

Aun aceptando que el papel del Estado en la producción del Bienestar ha sido, es y será importante, no hay ninguna razón para sostener que el único modelo viable de Bienestar sea aquel donde el Estado asuma un papel monopolista en la producción del Bienestar. Porque, al igual que tantas otras cosas, el Bienestar también se produce, y, además, siguiendo las lógicas racionalizadoras del cualquier sistema productivo de bienes o de servicios. Hasta ahora, en el modelo del Estado de Bienestar, el Estado ha asumido un papel principal (en la mayoría de las ocasiones monopolista, exclusivista) a la hora de producir Bienestar, de proveer de los principales bienes y servicios relacionados con el Bienestar que demanda cualquier sociedad moderna: salud, educación, seguridad en la renta de las personas envejecidas y enfermas, etc. Pero, por definición, esas necesidades, y las que se puedan ir añadiendo en los lógicos desarrollos sociales, no tienen por qué ser atendidas directa, total y absolutamente por el Estado. Incluso cabría poner en duda la legitimidad para que ocurra así. 


\section{EL BIENESTAR Y SUS POSIBLES TRANSFORMACIONES}

No debe extrañar que, aun desde una posición de duro criticismo hacia el Estado de Bienestar, se mantenga la idea del Bienestar cuando se analiza la fase posterior a la del Estado de Bienestar, cuando se analiza la transición hacia otro modelo como es el de la Sociedad del Bienestar. Modelo que incorpora en su título también el Bienestar. No creo que sea sensato ni realista hablar de transformaciones radicales del modelo de Estado de Bienestar. Más bien al contrario, su transición hacia la Sociedad del Bienestar implica eso, una transición gradual, moderada, incluso lenta. Una reforma y no una ruptura. Tres importantes razones avalan la tesis transicional y el mantenimiento del Bienestar como valor colectivo: 1) En primer lugar, precisamente por su componente de ideario cultural y valorativo; su gran éxito entre la ciudadanía; su identidad como valor cultural y político. 2) En segundo valor, porque ha sido capaz de definir sociedades enteras, yendo incluso más allá de la identificación bajo el formato de Estado de Bienestar. Realmente, si todo sale bien y se hacen los deberes correctamente, las sociedades del Estado de Bienestar de las pasadas décadas se transformarán en Sociedades del Bienestar, logrando una nueva identidad colectiva en torno a la idea de Bienestar. Se trata de una categoría tan poderosa que podría entenderse paralela de la clásica de países desarrollados y paises en vías de desarrollo. 3) Y, por fin, el tercer gran motivo es que la idea de Bienestar está íntimamente asociada a la paz y concordia sociales que vive Occidente, hasta el extremo que puede servir de indicador para otros países que buscan su equilibrio interno en los grandes acuerdos ciudadanos. El sentido común indica, pues, que la idea de Bienestar, redefinida, debe pervivir por el bien de la colectividad. El equilibrio social, siempre frágil, así lo exige.

El acceso a la Sociedad del Bienestar no debe implicar una seria ruptura o fractura histórica, sino un esfuerzo de reforma que permita la adaptación de un modelo social a otro con los mínimos traumas posibles. En consecuencia, en ese proceso transicional hacia la Sociedad del Bienestar, el Bienestar debe ser establecido atendiendo a cuatro parámetros fundamentales: 1) definición de las áreas específicas donde tiene su existencia natural; 2) su vinculación con la política económica; o, con otras palabras, replanteando la relación que debe existir entre política social y política económica; 3) la aparición de un nuevo espacio público, donde se encuentran las tradicionales esferas pública y privada; y 4) la compaginación de bienestar colectivo y bienestar individual. Estos cuatro parámetros delimitan bien el terreno de definición y asentamiento del Bienestar. Veámoslos uno a uno.

\subsection{Las áreas de implantación del Bienestar}

Las clásicas áreas de Bienestar han sido y seguirán siendo la salud, la educación, el trabajo, una jubilación digna y, en general, el mantenimiento de unas 
condiciones sociales generales que impidan la marginación social en cualquiera de sus formas. Lógicamente, este listado no debe ser considerado como cerrado; ni en el sentido de que se impida la incorporación de nuevos elementos, ni tampoco en el sentido de que no puedan eliminarse otros existentes. Realmente, este listado (repetimos, clásico) debe ser entendido como el fluido resultado de grandes acuerdos o pactos sociales registrados en países particulares y que se extienden con facilidad hacia otros. Así, no todas las llamadas sociedades industriales avanzadas compartirían todos y cada uno de esos elementos; y mucho menos ocurriría esto en las sociedades en vías de desarrollo. Como listado abierto, mutable en función de los sucesivos pactos sociales que se van produciendo, en los últimos tiempos se han incorporado con ímpetu a estos objetivos de genuina Política social cuestiones tales como la defensa del medio ambiente, la protección del menor, la vivienda, la defensa de la igualdad de género (mal llamada igualdad de la mujer), la defensa de cualquier tipo de minusvalía y la protección a la tercera edad. Dado que el acceso a la Sociedad del Bienestar debe producirse de la forma más consensuada posible, deben respetarse los grandes impulsos colectivos que sitúan nuevos problemas en el centro de atención de la idea del Bienestar.

\subsection{El entronque de la politica social con la política económica}

La política social que se desarrolle en la Sociedad del Bienestar no puede estar ya escindida de la política económica, como lo ha estado en la anterior situación del Estado de Bienestar. Recordemos que, en la anterior situación, se registraba una seria cesura entre una y otra debido a la concepción estatalista del Bienestar. En la versión tradicional (cfr. Briggs, 1961; Titmuss, 1958, 1968), el Estado recela del mercado provocando que los llamados poderes públicos (en definitiva, el Poder Ejecutivo) intervengan para modificar o corregir los efectos sociales del sistema económico entendido como un sistema orientado por las leyes del mercado. Puesto que, además, están en juego grandes valores colectivos, el Estado se arroga la más completa legitimidad para actuar de manera incesante recortando las actuaciones que proceden de la sociedad civil y del mercado. Esta es la forma en que se ha difundido una definición bastante pragmática de social policy, identificándola simplemente con la intervención pública dirigida al objetivo del bienestar colectivo e individual (en términos de seguridad, instrucción, salud, etc.), y en oposición a la política económica convencional. Esta versión, ya clásica, del Estado de Bienestar presupone erróneamente que la política económica es incapaz de atender la satisfacción de las necesidades sociales e individuales (vid. Marshall, 1963, 1981). Ya no estamos ante una complementación, sino ante una verdadera confrontación que ha definido bastante bien lo que fueron los Estados de Bienestar europeos: de la política económica no deben esperarse soluciones a las demandas que acoge la 
lógica del Bienestar; será la política social, diseñada y ejecutada por el Poder Ejecutivo, la que deberá ofrecer soluciones reales. De carácter estatal, claro está, mientras que la política económica está obligada a contar con las fuerzas del libre mercado. A este respecto, es especialmente interesante la clásica interpretación de Titmuss (1968), al entender la política social en términos de relaciones sociales y vinculada de alguna manera a una ética altruista; de manera que el Estado de Bienestar no sería sino la institucionalización del altruismo (Titmuss, 1968). Encontramos en Titmuss una de las mejores versiones de esto que decimos, traducida ya en los términos de filosofía política más correctos: la política social está interesada por los diferentes tipos de transiciones morales que en la sociedad moderna adoptan formas institucionales para crear y mantener las relaciones sociales y comunitarias. Y, de forma especial, en su obra póstuma Social Policy, Titmuss enfatiza que la política social, en último análisis, estaba obligada a atender los aspectos no económicos de las relaciones humanas, forzando al máximo la división entre relaciones humanas económicas y sociales. Sin embargo, como ha señalado Donati (1985), esta interpretación implicaría entender que lo económico es la antítesis de lo social, y viceversa; que lo económico, como el mercado, por ejemplo, es sustancialmente distinto de los ámbitos político y social; en definitiva, que la política social coincide necesariamente con la oferta pública de servicios y con el protagonismo estatal máximo. Sin embargo, está claro que la política social conecta de forma íntima con la política económica convencional, atiende relaciones sociales y también económicas de los beneficiarios, y no tiene por qué sustentarse necesaria y totalmente sobre el gran protagonismo del Estado, que sólo entiende de oferta pública de servicios, sin dejar margen ninguno a la posible y factible oferta de servicios públicos.

Efectivamente, la reducción de la política social a la administración social, implicando exclusivamente a los poderes públicos, enfrenta una grave contradicción que quizá sea una de las claves de la crisis fiscal del Estado de Bienestar moderno: a largo plazo, una buena política de inversión y localización empresarial, industrial y de servicios, que fomente el tejido y la actividad productivas, tiene más importancia para la determinación final del nivel de vida de una comunidad dada que una política de seguridad social basada en los clásicos mecanismos de subvención estatal. Entendida de esta manera, la política social conecta con la política económica general sin dejarse asimilar por ella, se aleja de la simple y clásica administración social basada en la protección subvencionada, e incorpora en su área de problemas las consecuencias sociales de todas las formas de inversión. $\mathrm{O}$, con otras palabras, si la administración social se interesa sobre todo por la respuesta institucional pública ante la demanda de satisfacción de ciertas necesidades sociales, la política social debería diferenciarse por el hecho de atender también el estudio de la creación y distribución social de esas necesidades y de su dependencia, yendo más allá de los meros mecanismos de transferencia presupuestaria. Para decirlo con R. Mishra, la política social debe ser considerada de forma amplia, como aquel modelo o 
mecanismo social interesado típicamente por la distribución de los recursos de acuerdo con algún criterio de necesidad.

La desconexión entre política social y política económica ha resultado ser muy peligrosa. Así, por ejemplo, la lucha contra el desempleo no puede ser sólo un objetivo de la política económica ni tampoco sólo de política social. Las repercusiones que puede tener el crecimiento del empleo se traducen en reducir o eliminar cuestiones que, consideradas desde la exclusiva óptica tradicional del Estado de Bienestar, en su vertiente de política social convencional, implicarían enormes gastos sin que sirvieran para paliar las situaciones. Handler ha señalado esta cuestión en un reciente libro donde examina los intentos de reforma de los programas de bienestar norteamericanos por parte del presidente Clinton: «Hacer que el trabajo pague — ha escrito Handler- Ese es el camino para reducir el problema más importante: la pobreza (...). La reforma del bienestar por sí misma no sirve para estimular el mercado de trabajo. Y, a menos que haya más empleos que sean remunerados con rentas más altas, no se habrá hecho nada para reducir la pobreza. Y, en la medida en que no hagamos nada con la pobreza, continuaremos condenando a la siguiente generación» (Handler, 1995: 150). En consecuencia, la Sociedad del Bienestar deberá contar con una armonía en el diseño, desarrollo, ejecución y corrección de la política económica y la política social.

\subsection{El nuevo espacio público, punto de encuentro de las tradicionales esferas pública y privada}

En demasiadas ocasiones, la literatura especializada no distingue con propiedad las esferas en que ocurren los fenómenos del bienestar. Y esta confusión es mucha más dañina para todos aquellos sujetos individuales que están implicados en alguno de aquellos fenómenos y no son capaces de delimitar su propia actuación, sus propias responsabilidades. Pensemos por un momento en un sujeto adulto que tiene un familiar anciano en casa, lo que le hace vivir una situación problemática. ¿Hasta qué punto existe una responsabilidad privada para hacer frente a esa situación? ¿En qué momento estará legitimado para solicitar la intervención pública? ¿Dónde situar la línea divisoria? Muchos ciudadanos viven situaciones similares; más de dos millones de hogares españoles, para ser más exactos. Y, si pretenden ser justos con ellos mismos y con sus conciudadanos, no les será nada fácil localizar ese punto de no retorno, esa divisoria entre su vida privada y su vida pública. ¿Por qué ocurre ese fenómeno? Debemos buscar la explicación algo lejos, en la separación inicial entre Estado y Sociedad que propició la posterior separación entre esfera pública y esfera privada. Una de las consecuencias del Estado Social es que volvió a reunirlas subsumiendo una en otra; y esta reunión pasó de forma integral al modelo del Estado de Bienestar (vid. Montoro y Montoro, 1996: 64-66). El resultado inmediato ha sido la aparición de una nueva esfera pública donde se encuen- 
tran privacidad y publicidad muchas veces de manera confusa (García Pelayo, 1981: 24 y ss.; Habermas, 1981: 181). Esta nueva y confusa esfera ha surgido porque Estado y Sociedad se han disuelto en un nuevo concepto: el Estado Social, lo que ha provocado que el Estado y la Sociedad hayan dejado de ser sistemas autónomos, autorregulados, transformándose en dos sistemas profundamente interrelacionados entre sí a través de relaciones complejas, con factores reguladores que están fuera de los respectivos sistemas, y con un conjunto de subsistemas interseccionados que hacen que el sistema estatal y el sistema social tengan que ser considerados como partes de un metasistema (García Pelayo, 1981: 25). Con otras palabras, podríamos decir que el Estado ha experimentado un proceso de socialización mientras que la Sociedad ha experimentado un proceso paralelo de estatalización. Esa nueva esfera no puede ser ya concebida ni como esfera puramente privada ni como esfera genuinamente pública. Ha surgido una nueva esfera social, repolitizada, que ha disuelto las tradicionales diferencias entre lo público y lo privado. Esto quiere decir, adicionalmente, que las acciones del Estado y de la Sociedad se modifican constante e imperceptiblemente de manera reflexiva, como consecuencia de la permeabilidad de uno y de otra. En definitiva, los límites entre el ámbito privado y el ámbito público se han difuminado. Y, en lo que concierne a nuestro tema, a partir de este momento no se podrá hablar de bienestar individual sin hacer referencia inmediata al bienestar público; y viceversa. Esta doble referencia a lo público y a lo privado es lo que hace tan complejas las llamadas sociedades del bienestar modernas. Y la importancia de la idea del Bienestar en la etapa posterior a la del Estado de Bienestar se fundamenta también en la aparición de esa nueva esfera. A partir de este momento, las demandas y necesidades sociales características de la situación del Bienestar tienen tanto una consideración pública como privada. Y así deben experimentarla los ciudadanos.

Volviendo a nuestro ejemplo inicial, ahora estamos en mejores condiciones para diagnosticar el problema de nuestro buen ciudadano por tener en su hogar una persona anciana. Para él será un problema personal, individual, particular; eso es indudable. Pero, simultáneamente, y no sólo debido al número de ancianos (es decir, no sólo debido a cuestiones de cantidad), será también una cuestión de interés público. Hay legitimidad para las dos perspectivas, aun cuando aparezcan inicialmente contradictorias y compliquen el diseño de estrategias para alcanzar una resolución satisfactoria. De forma inversa, la existencia de un mendigo que pide limosna puede y debe ser entendida por cualquier sujeto de igual forma, aun cuando no tenga relación personal ninguna con el mendigo.

Lo preocupante quizá no sea tanto el reconocimiento de esa simultaneidad en las responsabilidades privadas y públicas cuanto que, tal y como se ha desarrollado el Estado de Bienestar, con sus visiones forzadamente totalizadora y colectivizadora, cualquier cuestión social es definida como genuinamente pública, anulando o escondiendo la dimensión individual o particular. Los efectos de esta forma de entender las cosas han sido devastadores en una faceta: 
han estimulado el surgimiento de derechos y anulado la aparición de deberes. Es lo que Sartori (1993: 118 y ss.) ha denominado la sociedad de las expectativas, que después examinaremos con alguna mayor atención. Una sociedad donde los ciudadanos se sienten titulares de débitos, donde esperan cosas que ellos consideran que se merecen por ser ciudadanos y sobre las que carecen de responsabilidades personales o privadas. Ha sido el Estado, bajo la forma del Estado de Bienestar, el causante de esa situación, mientras que el ciudadano repercute y amplifica el mensaje hasta el infinito. Los privilegios contra los que pretendía luchar el Estado de Bienestar, introduciendo un igual rasero para todos, ha impedido ver que esos privilegios comportaban, es verdad, derechos, pero también deberes. Y ocurre que «los privilegios se transforman en derechos cuando se hacen iguales; no sólo los mismos para todos, sino también ampliados a todos» (Sartori, 1993: 119). La cuestión clave en la transformación de la sociedad medieval en una sociedad moderna se localiza en la evolución del equilibrio entre derechos y deberes. En la actualidad, el Estado de Bienestar ha provocado un serio desequilibrio, y "hoy día la conexión entre derechos y deberes se ha roto, y, además, los derechos ya no son iguales en el sentido de que no son los mismos para todos: son mayores para algunos y menores para otros» (Sartori, 1993: 119). A nuestro ciudadano que tiene problemas en casa por tener un anciano se le ha hecho entender que él es una víctima, que no tiene deberes como sujeto individual, y que sólo tiene derechos ante alguien (obviamente el Estado) para que le solucione el problema. Esta visión ha generado multitud de situaciones en las que los individuos particulares no tienen responsabilidad ni deberes contraídos. Esta visión ha forzado la reunión de las dos esferas en favor exclusivamente de la segunda, de la esfera pública. Sin embargo, la verdadera situación es bien distinta. La reunión de las esferas significa que todos y cada uno de los individuos tienen derechos y deberes que no pueden evitar. Será difícil deslindar entre uno y otro, es cierto. Pero la idea del Bienestar implica necesariamente llevar a cabo ese esfuerzo de dos maneras precisas: 1) desde el punto de vista del Estado, renunciando a convertirse en el gran agente que soluciona cualquier acontecimiento que afecta a cualquier ciudadano; y 2) desde el punto de vista del ciudadano individual, reconociendo que tiene ante todo deberes en relación consigo mismo, con su entorno inmediato y con la sociedad donde vive; y que, después, tiene derechos que podrá reclamar, y no necesariamente siempre en relación con el Estado.

\subsection{Bienestar colectivo y bienestar individual}

En ese marco, precisamente, es donde se localiza la misma definición de bienestar colectivo y bienestar individual. Es impensable gozar de bienestar individual si no existe bienestar colectivo; y viceversa. En una primera lectura, parecería que abogamos por la imposición de una perspectiva igualitarista. Pero la coincidencia de bienestar colectivo e individual no tiene por qué plan- 
tearse en términos de absoluta igualdad. Lo que está claro es que no son admisibles situaciones extremas donde unos pocos disfrutan de mucho mientras que otros no tienen nada. La clave que soluciona este aparente conflicto es la armonización media donde se registra la desigualdad. El bienestar colectivo puede ser medido a través de los clásicos indicadores o a través de otros que podamos inventar. $\mathrm{Y}$ el bienestar individual se fundamenta en una progresión individual que los sujetos puedan controlar individualmente; se basa en un estímulo de las iniciativas individuales para lograr cada vez mayor bienestar. El bienestar no se logra definitivamente; ni individual ni colectivamente. Por consiguiente, cualquier esfuerzo igualador conduce al estancamiento tan característico del Estado de Bienestar. Puesto que el bienestar colectivo es el resultado medio de los bienestares individuales, la clave del desarrollo de la idea de Bienestar debe desplazarse hacia la capacidad de realización individuales. Se trata de conciliar una y otra perspectiva, colectiva e individual.

\section{4. ¿REFORMAR EL ESTADO DE BIENESTAR?}

Debemos ser muy cautelosos cuando hablamos de reformar el Estado de Bienestar. Es cierto que, en términos de orden y concordia sociales, los peligros son muy claros. La oleada de huelgas que registró Francia en los meses de noviembre y diciembre de 1995 , a raíz de un programa de ajuste diseñado por el Gobierno Juppé que pretendía redefinir ciertos aspectos de las pensiones y los impuestos, incluyendo algunos recortes sociales, fue una buena muestra de lo que puede ocurrir cuando una población se ha habituado al fácil apoyo estatal, a la falta de esfuerzo, a la aparente solución de los problemas a corto plazo. Sin embargo, existe otra dimensión que tampoco podemos olvidar, y que Handler (1995) ha señalado con verdadera sensación de cansancio y aburrimiento. Los programas estatales del bienestar han experimentado constantes reformas tanto en Estados Unidos como en Europa. Dependiendo de los gobiernos, unas veces para incrementarlos, otras para disminuirlos, otras para hacerlos supuestamente más eficaces. Reformas dentro de la lógica del Estado de Bienestar, lo que implica reformar para que nada cambie. Unas veces, ciertos segmentos de la población (pueden ser jubilados, o mujeres solteras con hijos) son beneficiados por ellas; en otras ocasiones serán otros segmentos. Habría que pensar, incluso, en qué medida el conflicto intergeneracional que se vive en todos los países desarrollados tiene como raíz precisamente estas torpes reformas y ajustes (cfr. Pérez Ortiz, 1995, 1996). Todas estas reformas conducen al mismo punto: seguir incrementando el gasto público en su versión de gasto social, drenando financieramente la economía productiva, e hipotecando el futuro bajo la forma de déficits públicos extraordinarios y deuda pública a la que alguien deberá hacer frente en el futuro y en el presente con el pago de sus intereses. Estas reformas olvidan lo más importante: la vinculación del Bienestar con la economía. Su estrecha dependencia, que hace que los esfuerzos refor- 
mistas desde dentro no conduzcan a enfrentar los graves desafíos que trae consigo el Bienestar. Al efecto, Handler ha escrito lo siguiente: "Si la economía crece, la reforma del bienestar se disuelve y pierde importancia para desahogo de los políticos responsables. Si la economía se estanca y crecen los niveles de inseguridad económica, la reforma del bienestar surge como un gran asunto político, y ya nos vemos de lleno una vez más en otra ronda de reformas. ¿Por qué? —se pregunta Handler-. ¿Qué está ocurriendo? ¿Por qué esa obsesión con la reforma del bienestar?» La explicación es muy sencilla y bien correcta. Según Handler, lo que ocurre es que «los políticos y la población en general entienden que la reforma del bienestar es mucho más prioritaria que la reforma de los sistemas de salud, la reducción del déficit, o la economía. Y, aunque tenemos muchos problemas sociales y también muchos problemas con las familias y los niños, con la delincuencia y las drogas, los problemas de los sistemas de salud, la reducción del déficit y la economía son problemas mucho más importantes que los asociados con el bienestar» (Handler, 1995: 148).

Bienestar o economía productiva: ésa parece ser la dicotomía que se está planteando. Elegir entre una y otra sin entender que no hay bienestar (bajo la forma de Estado de Bienestar o bajo la forma de Sociedad del Bienestar) si no contamos con una economía saneada, rica y con futuro. Este alejamiento de la realidad más obvia es una de las más terribles herencias que ha dejado el Estado de Bienestar. Si, además, vinculamos esta cuestión con el mercado de votos que da sentido a la democracia (Buchanan, 1978; Buchanan y Tullock, 1965; Downs, 1957), se entenderá fácilmente que las aparentes virtudes del Bienestar llegan con mayor facilidad a la población que las exigencias de la economía de mercado. Aunque lo que lleguen sean mentiras o verdades a medias, extremadamente peligrosas a medio y largo plazo para el equilibrio social.

Los esfuerzos que la práctica totalidad de los países europeos están haciendo por ceñirse a los criterios de Maastricht están vinculados al saneamiento de sus economías y parecen ser prometedores. Así, para el año 1997, Francia se ha planteado la supresión de 7.000 funcionarios y la revisión y/o supresión de algunas ayudas dirigidas al desempleo que se consideran mal adaptadas. En Alemania se pretende reducir en un 25 por 100 la asistencia social para desempleados que declinen efectuar trabajos que las autoridades estimen como adecuados para ellos; asimismo, se pretende elevar de 60 a 65 años la edad de jubilación de las mujeres y de 63 a 65 años la de los hombres, con el fin de reducir el peso de las pensiones en el gasto estatal. En Suecia, el gobierno socialdemócrata intenta recortar distintos programas de protección social en el ámbito general de una seria preocupación por lograr una economía más competitiva. En Dinamarca se han recortado gastos en la sanidad pública y en las pensiones por jubilación anticipada, y se pide a los parados de larga duración que lleven a cabo trabajos de interés comunitario para seguir percibiendo el subsidio. La misma línea seguida en Gran Bretaña, donde está planteado un serio debate sobre la necesidad de hacer obligatorios trabajos para la comunidad si se pretenden recibir prestaciones por desempleo. En España, los funcio- 
narios han visto congelados sus salarios y se han acometido diversas iniciativas de ahorro del gasto de las Administraciones. Y ya por fin, fuera de Europa, en Estados Unidos, el ejecutivo demócrata ha aprobado una ley que suprime la garantía de asistencia social a los pobres y limita la posibilidad de ayuda a los ciudadanos a un máximo de cinco años; una medida acompañada por una reducción drástica de la ayuda estatal a los inmigrantes, y por la garantía de que los distintos Estados deberán asegurarse de que al menos la mitad de los perceptores de ayudas públicas realicen trabajos de interés comunitario. Medidas todas ellas de diversa valoración, pero que muestran una preocupación generalizada entre los responsables de los gobiernos donde existen Estados de Bienestar avanzados. Pero quizá lo más esperanzador de algunas de ellas es que intentan sintonizar con una economía más saneada que sea capaz de generar más riqueza para todos.

\section{LA INCESANTE DEMANDA DE SERVICIOS: LA ECLOSION DE DERECHOS Y LA DESAPARICION DE DEBERES}

Uno de los efectos más característicos del Estado de Bienestar ha sido estimular al máximo la demanda de bienes y servicios por parte de la ciudadanía. Este efecto es reconocido por todos, defensores y críticos de este modelo, aunque, lógicamente, formulando valoraciones bien distintas. De cualquier forma, nos interesa resaltar dos importantes consecuencias que ha tenido ese mismo fenómeno: 1) la implantación y arraigo de derechos por parte de los ciudadanos; y 2) el crecimiento del Estado al objeto de atenderlos. Derechos y demandas han ido unidos, aunque tengo la impresión de que, al menos en el caso español, las demandas han ido por delante de los derechos. Incluso, para ser más precisos y siempre en el caso español, lo que realmente ha ocurrido es que el Estado desarrolló una intensa y extensa oferta que generó y definió la demanda y que acabó tomando la forma final de los derechos; y siempre yendo más allá de lo dictado por la Carta Magna. El Estado de Bienestar ha tenido y tiene mucho que decir en la generación de esos derechos. Derechos y Estado crecientes son fenómenos que se han producido simultáneamente. Cuantos más derechos, más Estado; cuanto más Estado, más derechos. La constante generación de demanda y derechos se ha convertido en la principal fuente de legitimidad del Estado de Bienestar. Este existe porque hay demanda y derechos, al margen de la auténtica fuente que los origina. Cabe pensar, incluso, que el Estado ha usurpado a la sociedad civil su natural papel de generador de demandas privadas y públicas en un intento por mantener y reforzar su papel público ad nauseam. Entra dentro de la lógica de generosidad del Estado de Bienestar entender que los ciudadanos individualmente considerados no son responsables prácticamente de nada, y que es el Estado el que debe asumir la responsabilidad por ellos. Así se establece en las Constituciones de las naciones que han desarrollado el Estado de Bienestar. Derecho al trabajo, derecho a la 
vivienda, derecho a la educación, y así sucesivamente; expresando con simples frases cuestiones sumamente complejas que tienen graves repercusiones económicas, colectivas e individuales. Derecho al trabajo, pero ¿qué tipo de trabajo?; ¿bajo qué condiciones?; ¿en qué marco de regulación laboral?; ¿cualquier trabajo para cualquier persona? Derecho a la vivienda ¿regalada, subvencionada? ¿O se trata sólo de impulsar algún tipo de política pública de suelo? ¿O quizá algo menos, algún tipo de regulación jurídica que estimule la construcción de viviendas? Con tamañas o superiores ambigüedades podríamos ir desgranando todos y cada uno de los clásicos ingredientes del Estado de Bienestar cuando se formulan tan graciosamente; ingredientes que han sido considerados por la población como derechos materiales, hasta el extremo de que cada uno de los ciudadanos piensa que son suyos al margen de su situación socioeconómica, por el simple hecho de ser ciudadanos. Obviamente, cuando se hace así, el sujeto activo debe ser el Estado, y el pasivo el ciudadano. La fórmula todo para todos y cada uno sólo admite una solución: el Estado resolverá, y ante él plantearemos nuestras quejas.

La sociedad del Estado de Bienestar es una sociedad de enorme oferta estatal, es cierto; pero también es una sociedad de enorme demanda. Es una sociedad donde se ha implantado el derecho a recibir, y no el deber de dar. Una sociedad en la que el Estado sirve a los ciudadanos, y no los ciudadanos al Estado. Todos tienen derecho a cualquier cosa. El Estado proveerá. Se trata de un modelo social que, como dijimos más arriba, Sartori ha denominado como la sociedad de las expectativas (Sartori, 1993: 118). Todos los ciudadanos tienen expectativas de derechos; todos se sienten titulares de débitos, de cosas que esperan y que, según la doctrina oficial del Estado de Bienestar, alguien les debe por el simple hecho de ser ciudadanos de un Estado o nación. Este principio parece haber calado muy hondo entre los españoles después de trece años de construcción del Estado de Bienestar a la usanza de los países centroeuropeos de los años sesenta y setenta, pero sin contar ni con los medios ni con la coyuntura. Tan hondo ha calado que una encuesta del CIS correspondiente a 1995 (Estudio CIS 2187, julio 1995) desvelaba que el 62 por 100 de los españoles estaba de acuerdo con una frase como la siguiente: El Gobierno es el responsable del bienestar de todos y cada uno de los ciudadanos y tiene la obligación de ayudarles a solucionar sus problemas. Mientras tanto, sólo el 16 por 100 se mostraba de acuerdo con la tesis contraria: Los ciudadanos son los verdaderos responsables de su propio bienestar y tienen la obligación de valerse por si mismos para solucionar sus problemas.

¿Cómo puede entenderse un fenómeno así? Obviamente, la pretensión igualadora del socialismo actúa como motor o fuente última desde donde mana una doctrina de este estilo. Pero para captar en su auténtica dimensión de estructura social el significado del juego de oferta y demanda, derechos y deberes, hemos de remontarnos al modelo social anterior al contemporáneo. Es decir, remontándonos a la sociedad feudal, como hace el mismo Sartori, podremos entender bien el alcance de lo que está ocurriendo. Es cierto que la 
sociedad feudal, la sociedad medieval, lo fue de privilegios. Distintos estamentos sociales poseen distintos privilegios, y las sólidas barreras estamentales impiden el libre acceso individual de unos a otros. Las barreras actúan, además, de manera rígida, en absoluto flexible. La desigualdad estamental, que se transforma en desigualdad individual, es un pilar de esa sociedad. Sin embargo, no debemos olvidar que, junto con la existencia de privilegios, los estamentos soportaban obligaciones tan taxativas como aquéllos. Así, por ejemplo, el privilegio del señorío de tierras y gentes llevaba consigo la obligación de la defensa por las armas. El señor que poseía una aldea la vigilaba y se beneficiaba de ella en razón de sus privilegios, pero también estaba obligado a defenderla. Privilegios y obligaciones en una balanza que debía equilibrarse lo más perfectamente posible. En la evolución del tiempo, ocurre que los privilegios se transforman en derechos cuando se hacen iguales. De alguna manera, el concepto de privilegio ha pasado al modelo de Estado de Bienestar privado de su significado social y estamental. El Estado de Bienestar ha resucitado el privilegio y lo ha extendido a toda la población; ha implantado un modelo social donde impera el principio de derechos iguales para todos, sin que se haga mención a la contrapartida: a los deberes. Un sistema social donde se ha perdido el equilibrio entre derechos y deberes, algo fundamental para mantener un equilibrio social elemental.

Conviene distinguir aquí dos cuestiones muy importantes: 1) el hecho de que estamos hablando de derechos formales y materiales; y 2) que el Estado de Bienestar ha afrontado la igualdad formal para todos, pero no la igualdad material. Esta confusión entre la dimensión formal y la dimensión material se encuentra en la opinión pública, en cualquier ciudadano que no acaba de entenderla. $\mathrm{O}$, con otras palabras, ocurre que, utilizando una vía igualitaria (formal), se llega a situaciones desigualitarias (materiales) exacerbadas por la expectativa de derechos para todos. Rawls (1971) ha sintetizado bien lo que ocurre en un sencillo criterio: a quien tiene menos se le debe dar más, con el resultado final de que los derechos se vuelven desiguales a causa de la igualdad compensatoria. Ningún político defensor del Estado de Bienestar se atreve a desvelar la confusión ante el ciudadano-elector. Sería excesivamente peligroso que, con una mano, se realizasen ofertas de una extrema generosidad y que presentan una supuesta imagen de igualdad (formal y material) para todos y que, con la otra mano, se desvelase el abismo que existe entre lo formal y lo material en una economía de mercado, por muy social que se pretenda que sea. Esta es una de las muchas contradicciones del Estado de Bienestar tal y como lo hemos conocido.

Por consiguiente, la sociedad del Estado de Bienestar es una sociedad desequilibrada en sus fundamentos más básicos o, al menos, situada en un equilibrio inestable y difícil de reequilibrar. La razón de esto se encuentra en que se trata de una sociedad de derechos sin deberes, y también de derechos desiguales (Sartori, 1993: 120). Cualquier sociedad necesita alguna fórmula saludable de equilibrio entre derechos y deberes, de manera que la balanza no se venza 
sustancialmente en ninguno de los dos sentidos. Eso quiere decir exactamente equilibrio. Se trata de una exigencia no sólo de carácter moral y ético, sino también de carácter material y formal-jurídico. Es la mejor forma de distribuir tanto principios morales como bienes, servicios y mecanismos productivos privados y públicos; capital humano y capital físico. Un equilibrio que fundamente la existencia de una sociedad libre capaz de gestionarse a sí misma y reequilibrarse también por sí misma (Sartori, 1993: 119). El Estado de Bienestar ha vulnerado estos principios básicos al quebrar la relación que debe existir entre derechos y deberes. Movido por una filosofía igualitaria, el Estado de Bienestar ha llegado a crear una situación en la que los derechos ya no son iguales para todos, ya no son los mismos para todos. Son mayores para unos y menores para otros. De alguna forma, el Estado de Bienestar hace que se registre un retroceso: una vez andado el camino que conducía desde los privilegios a los derechos, vamos hacia atrás desde los derechos a los privilegios, pero, esta vez, generando expectativas de privilegios que carecen de obligaciones en un proceso de desestructuración social de gran magnitud.

Recordemos que las llamadas revoluciones burguesas estuvieron movidas fundamentalmente por la conquista de derechos formales, y no tanto materiales. Los nuevos derechos civiles y políticos, puestos de relieve en las Constituciones de los siglos XVIII y XIX, se conforman como derechos jurídico-formales que no tienen una traducción inmediata en términos de beneficios materiales sustantivos. Son unos derechos fáciles de repartir entre la población y que significaban la superación de las arcaicas formas sociales estamentales. Unos derechos capaces de articular un nuevo orden social. El Estado de Derecho significaba la instauración de estos derechos formales, mientras que el Estado de Bienestar, intentando dar un paso más, llega a alcanzar los derechos sociales o económico-materiales. El resultado final es que la sociedad del Estado de Bienestar es una sociedad de expectativas de reivindicación de derechos materiales, de los ahora llamados derechos sociales. Pero estos nuevos derechos generan beneficios inmediatos, son costosos, gravosos, y alguien debe pagarlos. No son ya derechos formales, sin coste alguno. Como señala Sartori (1993: 123), los derechos formales son derechos absolutos, incondicionales, mientras que los derechos materiales están condicionados forzosamente por las disponibilidades materiales. La contradicción está en que el Estado de Bienestar los ofrece como si fuesen derechos formales; la contradicción está en que, por consiguiente, la población los percibe y reclama como derechos absolutos, como si no tuviesen coste social y económico alguno. Se trata de un error histórico de extrema gravedad. Porque «equiparar los derechos materiales con los derechos formales no es solamente un error de concepto, es también una estupidez práctica que transforma una sociedad de beneficiarios en una sociedad de la protesta de los descontentos» (Sartori, 1993: 123). La sociedad del Estado de Bienestar estaba abocada desde un principio al fracaso material y financiero, poniendo en peligro incluso el modelo democrático sobre el que se asienta. 
$\mathrm{Y}$ es que «la democracia se encamina hacia el déficit porque está estructuralmente indefensa, porque ha perdido al guardián de la hacienda» (Sartori, 1993: 123).

\section{LOS AGENTES VINCULADOS AL BIENESTAR}

El Bienestar no es ni puede ser exclusivamente el producto o resultado final de la acción estatal. O, al menos, no puede ser así en una sociedad regida por normas democráticas; en una sociedad libre. Podrá serlo en una sociedad totalitaria, planificada; pero eso ya no es Bienestar (García Pelayo, 1981). Porque el Bienestar, o existe en un modelo político de democracia y libertades, o es cualquier otra forma de protección o intervención tiránica y dictatorial, y deja de ser Bienestar. Sobre esa base democrática, el Bienestar es y debe ser entendido como el producto o resultado final de toda la sociedad. Así, los tres grandes agentes productores de Bienestar son el Estado, el mercado y las familias. Son los tres agentes que poseen la sensibilidad necesaria y la posición social requerida para definir las necesidades e intentar satisfacerlas. Son, por tanto, las tres grandes fuentes del Bienestar (vid. Rose y Shiratori, 1986). Cabría añadir un cuarto agente: las asociaciones de voluntarios, que, con sus acciones, no buscan rentabilidad económica y que, sin embargo, están desempeñando un significativo papel en la producción y/o gestión del Bienestar (Smith y Rosenbaum, 1981; Thompson, 1983; Weisbrod, 1977; White, 1981; Kramer, 1981). Sin embargo, estas asociaciones se mueven entre dos alternativas constitutivas: a) Por un lado, pueden estar vinculadas al Estado, que les facilita el apoyo, la regulación administrativa y la financiación necesaria para sobrevivir. En la medida en que están próximas al Estado de esta manera, pierden su identidad a los efectos de nuestro análisis, y pueden ser entendidas en la órbita estatal. b) En la segunda alternativa, esas asociaciones pueden no vivir a costa del Estado, sino operar de manera autónoma, lo que las sitúa, entonces, en la órbita del mercado. Una vez más, perderían su identidad social propia, y bien pueden ser entendidas dentro de aquel parámetro del mercado que acabamos de definir. Por consiguiente, no las consideraremos como agentes sociales de la misma magnitud que los otros tres, y podrán ser interpretadas al hilo de los análisis que hagamos tanto del Estado como del mercado. Estado, mercado y familia, pues, son los genuinos agentes productores del Bienestar. Lo han sido, incluso, en las etapas más estatalistas del modelo de Estado de Bienestar, aunque muchas veces se haya ocultado. Y, sobre todo, lo serán en la futura Sociedad del Bienestar. Como ha escrito Rose, «argumentar que no hay sitio para la familia y el mercado en la producción de Bienestar es adoptar una posición totalitaria que hace al Estado responsable de todo lo que sucede en la sociedad» (Rose y Shiratori, 1986: 13).

Para considerar adecuadamente el papel que juegan el mercado y la familia en la producción del Bienestar debemos despejar antes dos ideas erróneas: 
a) pensar que el Bienestar debe ser medido en términos exclusivamente monetarios (vid. Rose y Shiratori, 1986: 14); y b) sostener que deba estar fuera de cualquier esfuerzo monetarizador. Entendemos por monetarización del Bienestar dos cuestiones relacionadas estrechamente entre sí: la necesidad de pagar con dinero para recibir Bienestar y la necesidad de traducir el servicio de Bienestar en términos de costes reales (monetarios). Algunas facetas del Bienestar son susceptibles de monetarización y otras no; y, además, en algunas ocasiones podrán ser monetarizadas y en otras no será conveniente hacerlo. Hacer Bienestar es hacer política, y la política debe ser flexible para adaptarse a tiempos distintos y a grupos sociales diferentes. Algunas actuaciones que el Estado de Bienestar ha presentado como si estuviesen naturalmente al margen de cualquier monetarización no tienen por qué seguir estándolo. Realmente, en el antiguo modelo, el Estado intentó encontrar un punto intermedio, una tercera vía, y ofrecer una imagen de ausencia de monetarización de los servicios de Bienestar que ofrecía. Pero se trata de una ilusión falsa que esconde agresivas iniciativas fiscales de repercusiones bien conocidas.

Es innegable que el mercado y la familia producen bienestar; el mismo Titmuss (1968) lo reconoce de esta manera. Lo hicieron en el pasado (con y sin Estado de Bienestar), lo hacen ahora y, sobre todo, lo harán de forma mucho más activa en el futuro. Con monetarización o sin ella porque, en muchas ocasiones y ante el tamaño del déficit público crónico que viven los países del Estado de Bienestar, el problema de la monetarización es de carácter menor y esconde otros problemas mucho más graves: el coste, la gestión, la racionalidad en la prestación del servicio, etc. Pero veamos con algún detalle en qué medida tanto el mercado como la familia pueden ser solventes agentes de provisión de Bienestar.

\subsection{El mercado}

En el ámbito del mercado interesa distinguir dos actuaciones especialmente importantes: 1) las que se producen a través de las empresas (en la relación empleadores-empleados), en los centros de trabajo; y 2) las desarrolladas por todas aquellas agencias que facilitan bienestar utilizando los mecanismos clásicos del mercado. Es decir, por un lado, empresas que producen otro tipo de bienes y servicios, y que, en su interior, proveen de Bienestar a sus empleados; $y$, por otro, empresas que se orientan a proveer Bienestar directamente acatando las reglas del mercado. La presencia del mercado en la provisión de Bienestar es tan rica y amplia que, como sugiere Rose, "una cuidadosa especificación de las condiciones de producción y consumo de Bienestar mostraría que la producción nonprofit de Bienestar en escuelas, hospitales, centros de día y otros lugares es sólo una variante del mercado provisor de Bienestar. El hecho de que estas organizaciones no operen buscando el beneficio no quiere decir que sus trabajadores trabajen por nada. [Todos ellos] esperan que se les remu- 
nere por el trabajo que hacen»(Rose y Shiratori, 1986: 17). Las empresas convencionales que no buscan directamente el Bienestar lo facilitan de muchas formas: mediante entrenamiento y aprendizaje para atender la necesidad de educación y formación de sus empleados; facilitando pensiones privadas de jubilación y de enfermedad; cotizando por sus trabajadores; a través de guarderías de empresa; facilitando transporte; facilitando medios para la educación de los hijos de los trabajadores; facilitando el ocio y la recreación de sus empleados; etc. Todo ello ocurre dentro del ámbito laboral, en el marco de las relaciones sociales y sindicales del mundo del trabajo, dentro de la lógica que se conoce con el término de democracia industrial. El Bienestar que se obtiene de esa manera en el mundo laboral suele pasar desapercibido al ser considerado en un ámbito estrictamente privado. Sin embargo, posee una magnitud extraordinaria, forma parte de las negociaciones sindicales de cualquier gran y moderna empresa que se precie, y se ajusta al marco de los criterios de rentabilidad empresarial.

Y, en segundo término, las agencias que, operando con arreglo a la lógica del mercado, lo hacen dentro de los clásicos ámbitos del Bienestar. Colegios, residencias de ancianos, hospitales y un largo etcétera constituyen excelentes ejemplos. Obviamente, prestan el servicio a cambio de una contraprestación monetaria por parte del usuario y con carácter individual. Pero no estamos hablando ahora de las formas y cuantías de los costes. Cualquier acción de Bienestar tiene costes que alguien debe calcular y pagar; mediante pagos monetarios individuales o mediante exacciones fiscales. Hablamos ahora de las necesidades del Bienestar y de las agencias que las satisfacen. Y, en esta faceta, el mercado se ha mostrado muy ágil para adaptarse a las necesidades de Bienestar de una sociedad moderna.

\subsection{La familia}

La familia es la gran olvidada en todo lo que concierne al Bienestar (cfr. Goldschmidt-Clermont, 1982). Lo ha sido en el modelo del Estado de Bienestar, y no conviene que siga estándolo en la futura Sociedad del Bienestar. Al efecto, conviene distinguir entre las siguientes tres dimensiones de la familia: 1) como fuente de necesidades; 2) como facilitadora de actuaciones de Bienestar, sobre todo de forma complementaria y de forma inicial; y 3) como soporte completo de Bienestar.

1) Como fuente de necesidades, la familia ocupa un lugar de privilegio. Es en su interior donde suelen plantearse lo que luego, de forma agregada, constituirán las grandes necesidades sociales: educación de los hijos, mantenimiento de los ancianos, salud de sus miembros, ocio, etc. En la familia suelen nacer las necesidades sociales de Bienestar, y esto tiene la suficiente importancia como para rescatar el papel social del agente familiar. 
2) En segundo lugar, la familia facilita actuaciones de Bienestar con carácter iniciático y complementario. Asume la tarea de la educación de los hijos en las primeras fases de sus vidas, y, más tarde, complementa la actuación de los centros escolares. De igual forma actúa en materia de salud, de vejez, etcétera, hasta el extremo de que no puede pensarse que, prácticamente en ningún caso, ninguna institución estatal supla por completo la acción familiar; mientras que, al contrario, es más que frecuente que la familia supla al Estado.

3) Y, por último, la familia actúa brindando Bienestar a sus miembros por completo en muchas circunstancias: atendiendo enfermos, viejos, niños, soportando miembros de la familia desempleados y en muchas otras ocasiones. Contemplado de esta manera, la familia es una institución de Bienestar mucho más completa que lo que pueda ser nunca el Estado.

\subsection{La relación Estado, mercado y familia}

La relación entre Estado, mercado y familia es delicada, difícil; debe ser equilibrada; debe basarse en el complemento de esfuerzos. El modelo de Estado de Bienestar es profundamente desequilibrado en esta relación: desconfía del mercado por principios ideológicos y entiende que la familia le pertenece; el Estado interviene, regula y hace dependientes al mercado y a la familia. Sin embargo, debemos examinar con mucha cautela y también con mucho rigor en qué medida el Estado puede o no puede contribuir al Bienestar mixto; dónde, cuándo, de qué manera, con qué medios. Esa reflexión es fundamental tanto en términos políticos como sociales y económicos (Rose y Shiratori, 1986: 15). En la Sociedad del Bienestar estos tres grandes agentes deben mantener una relación realmente equilibrada; una relación donde no haya posibilidad de dependencias y subordinaciones como las que se registran en el modelo de Estado de Bienestar. Y, al hablar de dependencias, no estamos pensando en las regulaciones estatales bajo la forma de leyes, sino, ante todo, en los flujos económicos, que constituyen, sin duda, la fuente más importante de dependencia y subordinación. El Estado legisla; y, puesto que nos hallamos en democracia, es el mismo pueblo el que se otorga un marco jurídico-legal a través de sus representantes elegidos de manera democrática.

La complementariedad del Estado, el mercado y la familia debe producirse de manera acompasada, cubriendo los fallos y las disfunciones que cada uno de ellos pueden provocar. Así, el Estado puede ser insuficiente y debe ser corregido por el mercado y la familia (vid. Wolf, 1979; Peacock, 1982). O, también, la familia puede ser insuficiente, y el Estado y el mercado pueden actuar corrigiendo esa insuficiencia (vid. Flora, 1981). Y, por último, la familia puede compensar los fallos del mercado y del Estado (vid. Badelt, 1984). No es una cuestión nueva. Existe una abundante literatura en todas esas direcciones. Pero lo más importante es el mantenimiento del equilibrio entre los tres grandes agentes. 


\section{LOS ERRORES DEL PLURALISMO DE BIENESTAR}

La solución mixta del Bienestar está siendo confundida con mucha frecuencia por parte de los defensores del Estado de Bienestar con una suerte de solución plural que mantiene las bases del modelo de Estado de Bienestar. Conviene, por tanto, distinguir entre una solución y otra para evitar confusiones.

La última línea de defensa del Estado de Bienestar incorpora una interpretación plural basada en el mantenimiento del aparato estatal y de su poder económico, y asumiendo una delegación en la gestión y en la ejecución. Una delegación, claro está, que implica una permanente dependencia y subordinación hacia el Estado: no sólo el Estado es el que establece el espacio regulador (en términos jurídicos), sino que orienta las acciones a adoptar (en términos políticos) y las financia (en términos económicos). En consecuencia, este pluralismo que defiende la nueva izquierda no es más que formal, no sustancial. Y, desde luego, está muy alejado de la tesis que acabamos de sostener líneas arriba sobre la relación que debe existir entre Estado, mercado y familia. De hecho, esta visión plural no contempla en absoluto aquella relación. Lo único que hace es extender el brazo del Estado con agentes gestores que no pertenecen a la Administración pública, pero que viven de ella a todos los efectos; una especie de funcionarios privatizados. En el fondo late la clásica cuestión de la legitimidad del Estado, uno de los pilares argumentales de buena parte del neomarxismo moderno, y que se resiste a ser redefinido a fondo para adaptarse a los nuevos tiempos (cfr. Gough, 1979; Offe, 1984; también, Rose, 1984). Y es que hay mucho que redefinir. Quizá la cuestión del empleo sea una de las más importantes y llamativas por su trascendencia. Con demasiada frecuencia se escucha la tesis de que nuestro Estado de Bienestar está incompleto porque estamos lejos de alcanzar el pleno empleo keynesiano. De hecho, no es nada fácil encontrar entre los autores que defienden el Estado de Bienestar la adaptación de la lógica del empleo a los nuevos tiempos. Así, intentar mantener el nuevo Estado de Bienestar defendiendo el principio de pleno empleo y asociado a la crisis de desempleo que vive Occidente, especialmente Europa, lleva a muchos autores a conclusiones llamativas (cfr. Anisi, 1995). Para empezar, sorprende cómo el pleno empleo pensado para la década de los treinta sigue siendo utilizado como etiqueta sin modificar sus contenidos. Sigue siendo presentado como un suceso exclusivamente económico, sin considerar la carga sociológica que ha hecho que su sentido cambie radicalmente. Me refiero, obviamente, al simple hecho de que el pleno empleo keynesiano del Estado de Bienestar es masculino; en él, las mujeres carecían de espacio propio, no tenían pretensiones serias laborales porque el mundo del trabajo se basaba en un modelo familiar patriarcal, en una visión sociológica donde existía una clara diferenciación de roles: el hombre debía trabajar fuera del hogar y obtener una renta con su trabajo, mientras que la mujer debía hacerlo en el espacio doméstico sin derecho a renta (Giddens, 1994: 139; Fraser, 1987: 97). A finales del siglo XX una de las principales características del mercado de trabajo es la presencia femeni- 
na, que cualquier persona con sentido común aplaudiría por muchos motivos. Sin la presencia de la mujer, hoy estaríamos registrando pleno empleo en Occidente. Con ella pretendiendo lograr su espacio ocupacional, aún queda mucho camino, no sólo para atender a la población activa femenina que se declara como tal, sino para atender a la que, aún hoy, no se declara como demandante de empleo. El cambio cultural, sociológico, que ha propiciado esta nueva realidad no parece ser considerado suficientemente por esa economía que mira hacia atrás en el tiempo sin entender muy bien qué ha ocurrido. Esta falta de perspectiva, unida a otra idea gratuita según la cual en Occidente los niveles productivos son tan elevados y tan fáciles de conseguir que aseguran la existencia de una especie de estado de riqueza colectivo que recuerda los diagnósticos infundados de Herbert Marcuse en su El hombre unidimensional, parecen hacer concluir que nuestro desafío está antes en cómo redistribuir el excedente que logramos con tanta comodidad que en seguir creciendo de manera indefinida. Los países de nueva industrialización y los menos desarrollados están especializados en la producción de ciertos bienes y servicios vitales, y Occidente no puede competir con ellos. Sin embargo, la auténtica especialización de Occidente es la calidad de vida. Una vez más, el Estado vuelve a jugar un papel fundamental en esta óptica ideológica: el excedente no debe volver a los trabajadores en forma de salarios, lo que les convertiría en adocenados consumidores en una lógica consumista sin fin. Es el mejor ejercicio de demostración de que la noción de bienestar no es aséptica o neutral, sino que está cargada de valores (Mishra, 1990: 138; Judge, 1987). El Estado debe detraer ese exceso de renta productiva a través de los impuestos y transformarlos en bienes públicos que aseguren calidad de vida. Ocurre también con frecuencia que estos mismos autores tampoco confíen ya en el Estado gestor, con lo que proponen su transformación en Estado como organización intermedia (cfr. Anisi, 1995: 129130). Mantiene la titularidad, pero no la ejecución del servicio. Esta ejecución se realizará a través de empresas privadas que funcionarán siguiendo las reglas del mercado laboral pero no de la competencia y la rentabilidad, puesto que el Estado las subvenciona. Lo que producirán son bienes y servicios de Bienestar para todos; bienes públicos de los que todos disfrutarán.

Como ha señalado con acierto Mishra (1990: 138), tanto la literatura pluralista del Bienestar como cierta nueva izquierda confunden constantemente titularidad con gestión. Confusión que, en cada uno de los casos, se dirige hacia objetivos bien distintos. En ambos casos nos hallamos ante una interpretación errónea de la figura del Estado en la nueva Sociedad del Bienestar. Su papel debe quedar bien definido con arreglo a los siguientes tres principios: 1) Pérdida de poder centralizador y controlador. 2) Pérdida parcial de titularidad. 3) Pérdida parcial de ejecución. Este es el modo de permitir que mercado y familia puedan ocupar mayores cuotas en los tres parámetros fundamentales. Es importante que observemos la incapacidad de este enfoque por reconocer la existencia de una genuina crisis del Estado de Bienestar, por reconocer la necesidad de su reforma a fondo. Podemos encontrar esta incapacidad en los 
siguientes parámetros: 1) El bien privado sigue siendo perverso, mientras que el bien público es deseable. 2) El mercado es injusto y debe evitarse, mientras que el Estado será siempre justo y equitativo. 3) La población no debe alcanzar mayores niveles de renta porque eso sólo estimularía su ansia de consumo. 4) El Estado debe mantener la titularidad del Bienestar, aunque debe confiar en otros agentes la ejecución de los servicios. Sin embargo, su capacidad política y financiera no debe ser mermada.

La Sociedad del Bienestar es una sociedad mixta, en los términos que estamos planteando; o plural, si se quiere. Pero siempre en los términos planteados. Mishra (1990: 135) se equivoca cuando plantea que se trata de un cambio en la disposición del mobiliario del salón; cuando piensa que son cambios en la forma, no en el contenido. Los cambios que implican la Sociedad (mixta) del Bienestar que estamos sugiriendo aquí están más en la línea de lo formulado por Rose o Judge. Como ha argumentado Rose, "una crisis del Estado de Bienestar no es una crisis del Bienestar en la sociedad. En las sociedades mixtas, las familias tienen una multiplicidad de medios para mantener su bienestar» (Rose y Shiratori, 1986: 36). O, como sostiene Judge cuando intenta explicar la política thatcheriana de Bienestar, en Gran Bretaña «el Estado [no] está abdicando de su responsabilidad en la promoción del bienestar individual y colectivo. [La política social en el Reino Unido se está moviendo] desde un ethos predominantemente colectivista a una concepción más viable del Estado como un ente que favorece. [En este nuevo papel, el Estado pone más énfasis] en la financiación, planificación, promoción y regulación de los servicios que en la producción y previsión de los mismos» (Judge, 1987: 26).

\section{IGUALDAD DE OPORTUNIDADES Y DISCRIMINACION POSITIVA}

La igualdad ha sido uno de los clásicos sueños de la Ilustración, de la modernidad, traído a la era postmoderna. Mal entendido por los revolucionarios franceses, quienes, evidentemente, no pensaban exactamente en igualar a todos los seres humanos, se convirtió en bandera ideológica del socialismo y del comunismo. Pero es en el anarquismo donde se debe encontrar su verdadera proyección y plasmación.

La igualdad adquiere diversos formatos que podrían sintetizarse en cuatro principales (cfr. Sartori, 1992: 89): 1) igualdad jurídico-política; 2) igualdad social; 3) igualdad de oportunidades; y 4) igualdad económica (vid. Tawney, 1931; Bryson et alii, 1956; Pennock y Chapman, 1967; Oppenheim, 1968). No es necesario restar importancia a ninguna de ellas. Pero, al igual que hace Sartori (1992: 89), centraremos nuestra atención en la tercera: en la igualdad de oportunidades, que es la que mayor interés tiene en relación con el Estado de Bienestar.

Igualar a los seres humanos como sueño ha tenido una traducción en tér- 
minos de sensibilidad política que ha impregnado todo el siglo XX. Realmente, cualquier posición política no extrema acepta algún principio de igualdad. Pero los matices y sentidos varían sustancialmente. Obviamente, la dicotomía que más éxito ha tenido ha sido la establecida entre igualdad de resultados e igualdad de oportunidades. Es decir, situar el principio de igualdad al final de la carrera promocional de cualquier individuo o al principio. La igualdad de resultados, igualar a todos al final del trayecto, sólo ha sido realizada teóricamente por parte de las sociedades planificadas estatalmente, las correspondientes a lo que hemos conocido como socialismo real. Pero se trata de una realización sólo teórica. Las burocracias dominantes de esas sociedades se situaban en posiciones de privilegio a todos los efectos económicos, sociales y políticos, mientras también se ocultaban los sectores marginados. La igualdad de oportunidades, el crear sistemas que permitan que todos puedan competir desde posiciones similares, ha sido el mecanismo más admitido por su mayor sintonía con los modelos democráticos, y porque permite solventar situaciones de discriminación provocadas por posiciones de educación, salud o económicas no propias de los sujetos.

Pero sigue sin estar claro el auténtico significado de la igualdad de oportunidades. Así, por ejemplo, en su obra ya clásica (Equality), Tawney aborda el tema de la igualdad de oportunidades en sólo 18 páginas; y, en ellas, evidenciando serios problemas para explicitar una cuestión tan complicada, recurre a 20 metáforas aproximadamente en las que hace referencia, entre otras cosas, a tronos, asnos, zanahorias, renacuajos, escaleras, arrecifes, pararrayos y abismos. $\mathrm{Y}$ es que Tawney, maestro entre los maestros del igualitarismo, piensa en el fondo que la igualdad de oportunidades no es más que una ficción, no una realidad. Si hiciésemos una encuesta, obtendríamos que la población tiene en mente un número demasiado elevado de barreras que frenan la igualdad de oportunidades. "El 'beneficio' de la 'igualdad de oportunidades' — ha escrito West - es seguramente algo tan intangible que es inaccesible incluso al más ambicioso de los estadísticos. Incluso como objetivo social aproximado, no es fácil determinar lo que exactamente significa, o encontrarle una identidad consistente» (West, 1994: 79).

Realmente, como señala Sartori (1992: 90), dentro de la idea de igualdad de oportunidades se esconden dos cosas distintas. Es decir, no hay realmente una igualdad de oportunidades, sino dos: una igualdad de acceso y una igualdad de partida. Con igualdad de acceso se quiere decir «igual reconocimiento a igual mérito, [lo que] se traduce en la mayoría de las ocasiones en la fórmula de la 'carrera abierta al talento', en función, y únicamente en función, de la capacidad y de los méritos» (Sartori, 1992: 90). Con igualdad de partida quiere decirse «igualdad de condiciones iniciales (para lograr la igualdad de acceso)» (Sartori, 1992: 90), lo que implica una igualdad en las condiciones materiales y alude directamente a una igualdad económica, en la medida en que no hay condición material más sustanciosa que la económica. Sartori (1992: 91) formula sintéticamente una y otra con arreglo a principios y utilizando fórmu- 
las sintácticas muy divulgadas y admitidas. Sea como fuese, lo que no tolera una sociedad moderna es que existan barreras insalvables que impidan que todos tengan acceso a ciertas ocupaciones, profesiones o posiciones sociales. Todos en el sentido más nominal. Todos sin exclusión ninguna por razón de sexo, raza, origen social o capacidad económica personal o familiar de origen. Todos y cada uno exclusivamente en función de sus propios méritos y de sus propias capacidades, sin que sus orígenes sociales sirvan como obstáculos serios para ello. Dejadas a su arbitrio, las familias transmitirían su situación de ventaja o desventaja a sus hijos, impidiendo que compitiesen en un plano de igualdad. No hay altruismo ninguno en la más elemental idea de impedir que un sujeto valioso ocupe puestos privilegiados en la sociedad con arreglo a sus méritos. Hay egoísmo e interés social al pretender que las posiciones de mayor responsabilidad estén ocupadas por los más capaces. El sistema social se asegura de esta manera un funcionamiento mucho más eficaz; se asegura, en definitiva, su supervivencia y su prosperidad. Como hace años dijo un Ministro de Educación norteamericano (C. A. R. Crosland): «No deseamos una completa igualdad de renta, ya que la responsabilidad adicional y el talento excepcional requieren y merecen una recompensa diferencial» (cit. West, 1994: 84).

El problema no es fácil. No se resuelve definitivamente formulando el principio de igualdad de oportunidades, y de esto sabe mucho el Estado de Bienestar. Puesto que la sociedad está impregnada de desigualdades, para lograr una genuina igualdad de oportunidades para todos (ya sea en la modalidad de acceso, ya en la de partida), se debe lograr antes una adecuada igualdad de circunstancias, en la terminología usada por Sartori (1992: 91). Aplicado al caso de los niños puede entenderse muy bien. ¿Cómo logramos una igualdad circunstancial para todos los niños españoles si cada uno de ellos procede de familias con distinta capacidad económica, con distinto bagaje cultural, etc.? Podemos acordar eliminar criterios de género o de raza; pero incluso el potente instrumento nivelador que es la educación puede ser totalmente inútil si las barreras son demasiado serias (West, 1994: 80). Sin embargo, el problema es todavía más complicado. ¿Debemos nivelar también los talentos personales, las capacidades intelectuales, eso que llamamos inteligencia? ¿Y hasta qué punto esa inteligencia que porta el niño es deudora de su medio familiar? Nos enfrentamos con una circularidad bien conocida. Nuestros niños no flotan en el espacio, aislados. Tienen procedencia social; aun siendo niños, poseen atributos adscritos por el medio, no adquiridos. ¿Igualdad absoluta, total? Como ha escrito Rees, la igualdad máxima, absoluta o total «supondría que todos fueran tratados literalmente del mismo modo en todos los aspectos» (Rees, 1971: 98). Pero, si ya son diferentes de algún modo, si los tratamos por igual, no haremos más que reproducir la desigualdad ya existente. Queremos igualdad de oportunidades para que todos puedan optar a los mismos estadios finales, aunque sabemos que no todos lo lograrán. Y es que lo realmente interesante es la igualdad de oportunidades, no la igualdad de resultados. Aun así, como señala Sartori, «iguales tratamientos no llevan a resultados iguales y, viceversa, iguales 
resultados requieren tratamientos desiguales. El dilema es éste: para ser igualados (en los resultados), es necesario ser tratado de forma desigual» (Sartori, 1992: 96).

Existe un punto extraordinariamente importante en todo esto. Las metas finales deben establecerse con claridad para que los sujetos las conozcan; pero no pueden predeterminarse como resultados fijos. Con otras palabras, «iguales resultados postulan desiguales oportunidades» (Sartori, 1992: 96). Y aquí se encuentra la raíz del error del socialismo real y también de buena parte del socialismo democrático. El mensaje no puede ser: existe la meta y todos la alcanzarán al mismo tiempo; algún agente externo a los sujetos asumirá la responsabilidad de que así ocurra (normalmente, el Estado). El mensaje debe ser: existe la meta y no todos la alcanzarán al mismo tiempo. Todos conocen sus reglas, nada se oculta; pero alcanzarán la meta en un tiempo que estará en función de sus propias posibilidades. El ejemplo de la carrera de atletismo puede sernos útil. No todos llegarán al mismo tiempo, y todos los corredores lo saben. Sin embargo, hay un premio aguardando al primero que llegue o a los tres primeros; los demás no obtendrán premio alguno. La cosa es clara: «si insistimos en la igualdad de resultados, de ello se desprende que debemos penalizar la habilidad" (West, 1994: 88). Lo que debe evitarse es que existan distintas ventajas iniciales para algunos. Y, para corregirlas, parece que sólo tenemos la opción de que los corredores más aventajados se sitúen detrás de los menos aventajados. Pero si lo hacemos así, la carrera carecerá de sentido. Realmente, la solución al dilema está en aceptar o no la existencia de la carrera; la solución no está en lo que hay que hacer en el momento de la carrera, sino antes de la carrera. La igualdad de oportunidades, traducida ahora en estímulos hacia los menos aventajados, debe operar siempre antes de la carrera, de manera que no se alteren las reglas de la carrera; esas reglas desigualitarias en sus resultados. Los criterios fundamentales de esa prenivelación son los siguientes: 1) ningún corredor que demuestre capacidad de correr adecuadamente debe quedar fuera de la competición; 2) el corredor de mayor capacidad no debe ver mermadas sus posibilidades precisamente por tener más capacidad; 3) todos conocen las reglas de la carrera; 4) todos conocen su duración y dónde está situada la meta final; 5) todos saben que no todos llegarán al final con éxito. Esas son las reglas de la equidad donde quedan a resguardo los dos criterios básicos: 1) la carrera deberá ganarla el mejor; y 2) a nadie que pueda ganarla deberá prohibírsele correr. Los beneficios serán públicos y privados; sociales e individuales. Porque, efectivamente, "la igualdad de oportunidades como meta social es directamente proporcional a la igualdad de oportunidades como meta personal» (West, 1994: 92).

Las políticas que utilizan la igualdad de oportunidades exigen intervenir para propiciarla. Intervenir compensando desigualdades previas. Y el problema está en dónde situar los límites y criterios de la intervención; qué nivelar y cómo hacerlo. Como escribe Sartori, «toda redistribución basada en una determinada característica perjudicará a las distribuciones que resultarían de otras 
características (...). Un exceso de tratamientos desiguales lleva más fácilmente a una guerra de todos contra todos, de privilegios contra privilegios, y no a la satisfacción de demandas igualitarias. Si toda igualdad se consigue generando otras desigualdades (...), entonces estamos desembocando en un círculo vicioso» (Sartori, 1992: 97).

Las llamadas discriminaciones positivas parecen inevitables para asegurar algún buen rendimiento del principio de igualdad de oportunidades; pero son muy peligrosas por su carácter deslizante (se sabe dónde empiezan, pero no dónde acaban) y por los agravios comparativos que generan en relación con otros segmentos poblacionales. Este ha sido uno de los principales problemas del Estado de Bienestar, y con toda seguridad pasará a serlo en cualquier modelo de Sociedad del Bienestar que se diseñe. Las claves a resolver aquí son: qué tipo de política de discriminación positiva; para quién; durante cuánto tiempo; quién la diseña; quién la ejecuta; quién decide su finalización. La única solución posible es la gestión moderada de cualquiera de estas políticas. La única solución posible es el mantenimiento del "contraequilibrio de desigualdades» (Sartori, 1992: 99). No conseguiremos eliminar las desigualdades, ni tampoco se pretende hacerlo de manera tan absoluta como ha sido presentado (falsamente) por el Estado de Bienestar. Sí debe conseguirse eliminar parcialmente el acceso desigual a las oportunidades por razón de género, etnia, origen económico y origen social. Es decir, ninguna de las dimensiones grupales (tribales en muchos casos) puede articular el principio de la igualdad de oportunidades de manera absoluta. Debe dejárseles espacio suficiente a los individuos para que alcancen la libertad de acción incluso al margen de sus grupos de origen. Con otras palabras, el estímulo a grupos marginados no puede ser una coartada para estimular individualidades inadecuadas ni para frenar el estímulo de individualidades que lo merezcan. El fondo del problema es que el Estado de Bienestar ha trabajado en el espacio creado por la dicotomía grupos-instituciones. Sin embargo, la Sociedad del Bienestar debe trabajar con el eje individuo-grupo-institución. Y, en ese eje, cada uno de los protagonistas debe asumir sus propias identidades y responsabilidades. Expliquemos una y otra cosa.

El Estado de Bienestar se ha insertado dentro de lo que Raymond Aron llamó el vasto proyecto igualitario. Nunca pretendió alcanzar la igualdad de resultados, pero en su insegura y confusa lectura de la igualdad de oportunidades actuó polarizando instituciones y grupos sociales. Instituciones (estatales, claramente) porque deberían ser las agencias que diseñarían las actuaciones precisas y las ejecutarían. En ese terreno en el que se producía una mezcla de imposición, control y poder sobre el resto de los agentes sociales, nadie mejor que las instituciones estatales sabrían cómo diseñar y ejecutar el bienestar de los demás. Y grupos sociales como un derivado de las disueltas clases sociales. Quebrado el paradigma de las clases y su papel en la sociedad, paradigma que se encontraba en el núcleo central de las ideologías que abastecían el Estado de Bienestar, no hay solución práctica ni ideológica a esa quiebra, con el resul- 
tado final de que las clases sociales son sustituidas, de facto, por los grupos sociales (vid. Pakulski y Waters, 1996: 132 y ss.). Buena parte del bagaje clásico de las clases pasa a los grupos, en una equivocada trasposición ideológica. $\mathrm{Y}$, así, nos encontramos con que nuestra sociedad está articulada, por un lado, por jóvenes, viejos, mujeres, gitanos, inmigrantes, niños, activos, ocupados, parados, trabajadores, etc. Y, por otro, las instituciones estatales. En liza, el Bienestar social. Ciertos criterios sirven para conformar esos grupos, sustituyendo a la ya periclitada vinculación con los medios productivos: la edad, el género, la etnia, la situación ocupacional, etc. La situación social del Estado de Bienestar se resuelve, así, en una especie de seudocorporatismo donde se incita la creación de todo tipo de grupos sociales que pretenden contar con parecidas claves de pertenencia e identidad que las anteriores clases sociales. El crecimiento exponencial de esos grupos es un fenómeno bien conocido, y resulta más que llamativo que a esto se le haya denominado el resurgir de la sociedad civil. Aparentemente, lo es; pero sólo en apariencia. Lo que separa el fenómeno radical e inevitablemente del genuino resurgir de la sociedad civil es que estos grupos sociales aparecen motivados por el Estado, que intenta conformar el Estado de Bienestar. O, con otras palabras, es la oferta pública la que ha creado esa manera de conformación de la sociedad civil, no la demanda, no las fuerzas naturales, asociativas y con intereses propios al margen de los estatales. Por ese motivo, los grupos sociales del Estado de Bienestar no coinciden perfectamente con las neocorporaciones; son distintas y han sido creadas por el Estado de Bienestar. El resultado final es una compleja red de relaciones sociales grupales carente de identidad propia, subsidiaria (y nunca mejor dicho) de las instituciones estatales que la crearon. Por eso cabe interpretar el Estado de Bienestar bajo este formato: instituciones estatales acaparadoras, administradoras y redistribuidoras frente a grupos sociales que buscan repartirse los medios y los impulsos que poseen las instituciones estatales. La subsidiariedad, la tutela, la servidumbre y, en definitiva, la falta de identidad son las características básicas de este remedo de sociedad civil que ha generado el Estado de Bienestar.

La Sociedad del Bienestar, como resultado transicional del desgaste y evolución del Estado de Bienestar, está obligada a introducir un nuevo elemento en esa forzada dicotomía: el individuo. Un elemento que producirá los siguientes tres resultados: 1) la relación final será tricotómica; 2) los grupos sociales deberán redefinirse bajo el impulso individual; 3) las instituciones estatales deberán perder su capacidad de coerción. Tres resultados que alterarán definitivamente el círculo vicioso que ha definido el Estado de Bienestar, que harán recuperar una auténtica sociedad civil donde los grupos no absorban y anulen a los individuos, y que devolverá al Estado un papel mucho más dependiente. Igualdad de oportunidades quiere decir, ahora, igualdad de circunstancias no sólo para grupos, sino también y ante todo para individuos.

Sociológicamente hablando y desde la perspectiva individual, nada sustancial debe querer decir pertenecer a un grupo social A ante la inserción en la 
estructura ocupacional; o, como mucho, muy poco. Se da por hecho que la pertenencia a un grupo social comporta beneficios colectivos e individuales, pero debemos empezar a reflexionar en qué medida comporta también perjuicios individuales. Así, por ejemplo, anteponer el grupo social a una profesión, unos estudios o unas actitudes sociales es distorsionar gravemente la realidad a costa de perjudicar la iniciativa individual. Definir un grupo social cualquiera como ha hecho el Estado de Bienestar implica que ninguno de sus miembros osará sostener que no pertenece a él. Planteado de esa manera, o se pertenece o no se pertenece a él, como si de una vieja clase social se tratase, pero en su fase más conflictiva y aguda. El individuo, la opción individual, queda aplastado por la presión que ejercen grupos sociales así definidos y por las instituciones estatales. La discriminación positiva, por tanto, se ejecuta a ciegas, de espaldas a cualquier opción individual. Ningún miembro del grupo social A o B podrá reclamar que, en un proceso de selección, no cuente su condición de miembro de ese grupo porque eso será imposible. De tal manera ha sido adscrito objetivamente utilizando algún criterio como los que hemos señalado más arriba. La discriminación positiva se convierte, de esta forma, en un entramado de concesiones a grupos sociales carentes de identidad, y, además, ejecutada de manera que, al final, se logra el enfrentamiento de esos grupos. Sencillamente porque no puede haber de todo para todos y en cada momento. El grupo social A se enfrentará con el grupo social $\mathrm{B}$, y éste a su vez con el $\mathrm{C}$ y con el D. Y así sucesivamente. $\mathrm{Y}$ un individuo que pertenezca circunstancialmente a los grupos $\mathrm{A}$, C y D podrá ser el máximo receptor de los beneficios que conlleva la coincidencia, pero también será un sujeto sobre el que caiga la mayor de las anulaciones individuales: no se sabrá si realmente es merecedor del reconocimiento o no. Su capacidad individual, su esfuerzo, su interés, no podrán ser argüidos so pena de ser arrojado fuera de todos esos grupos y entrar en una situación anómica extrema.

Con este diseño, característico del Estado de Bienestar, no cabe ningún estímulo individual sencillamente porque el individuo no existe. Una cruel paradoja para un sistema que, en teoría, intentaba proteger al máximo a los individuos fuesen como fuesen y estuviesen donde estuviesen. La igualdad de oportunidades, centrada, como vimos, en posibilitar que todos aquellos que poseen talento y capacidad puedan correr la carrera, queda ahogada en un ciego reparto grupal del que hay que esperar que no se beneficien aquellos que deben hacerlo, sino los que han sabido situarse correcta, astuta, estratégicamente en la estructura corporativa que negocia los recursos jurídicos y materiales que reparte el Estado. No sirven los clásicos criterios de género, edad, etnia, etcétera, para propiciar la igualdad de oportunidades, para canalizar debidamente las estrategias de discriminación positiva sin ahogar el esfuerzo individual. Los únicos realmente válidos son los del mérito y el esfuerzo personales. Y el Estado debe actuar en consonancia: reglas iguales para todos en lo que concierne a los requisitos formales de acceso a los mecanismos de movilidad social. Y eso al margen de la pertenencia a algún grupo social. La discrimina- 
ción positiva, que se concentra en los grupos sociales, debe tener una duración y alcance determinados previamente con el fin de que no ahogue la iniciativa individual. Dispensada de manera indefinida y tan extensa como la hemos conocido, propicia la ausencia del estímulo individual y refuerza el papel social de estos grupos tan endeblemente construidos y articulados. La Sociedad del Bienestar debe buscar mecanismos precisos para conciliar ambas cosas porque aún puede recoger una parte del espíritu conciliador del modelo del Estado de Bienestar encontrando «algo que pueda constituir un 'premio' adecuado para el individuo que triunfa y que, a la vez, no sea considerado como una penalización arbitraria (desigualdad) para sus vecinos con menos éxito (o menos trabajadores)»(West, 1994: 85). Si las reglas de juego son claras y justas, si no hay opacidad ni desventajas, quizá podamos ir desterrando poco a poco el espíritu caritativo y adscriptivo del Estado de Bienestar sustituyéndolo por un espíritu competitivo y de oportunidades, adquisitivo en definitiva, de mayor eficacia y resultados globales.

\section{CONCLUSIONES}

En definitiva, el Bienestar sobrevivirá al Estado de Bienestar. Su crisis no le arrastrará, sino que propiciará el surgimiento de otro modelo social que ya empieza a llamarse Sociedad del Bienestar. Un modelo donde el Bienestar será defendido por el mercado, el Estado y la familia. Un modelo donde podrá concitarse con mayor equilibrio lo individual y lo colectivo, articulado en el eje grupos-individuos-instituciones. Un modelo, en definitiva, donde el clásico Welfare no sea una forma de vida que alimenta el círculo de la pobreza, sino una oportunidad nueva para los individuos. Este cambio social implica la redefinición de algunos supuestos que han sido del Estado de Bienestar, y que deberán actualizarse para adaptarse a las nuevas circunstancias. En primer lugar, la demanda social de bienestar deberá definirse en un equilibrio entre lo colectivo y lo individual, lo privado y lo público, los deberes y los derechos. En segundo término, la política social implícita en cualquier dimensión de bienestar deberá sintonizarse con la política económica, buscando una sinergia que beneficie a los individuos. En tercer lugar, asistiremos a un resurgir de la dimensión individual compatible con nuevos agrupamientos sociales que son necesarios para articular una estructura social. Y, por último, el nuevo modelo social de bienestar deberá apoyarse sobre sólidas bases de igualdad de oportunidades y de un uso correcto de las políticas de discriminación positiva. Si algo hemos aprendido en estas últimas décadas es que jugamos con recursos escasos y que el esfuerzo individual es una pieza clave para generarlos y para pugnar por ellos. Si logramos situarnos en una posición en la que el beneficio individual sea identificado como beneficio colectivo, una posición en la que el capital humano (también escaso) esté mejor utilizado que hasta ahora, habremos dado un paso adelante en el progreso y el bienestar para todos. 


\section{REFERENCIAS BIBLIOGRAFICAS}

Aguila, Rafael del (1995): «El centauro transmoderno: liberalismo y democracia en la democracia liberal», en Fernando Vallespín (ed.), Historia de la Teoría Política, Madrid, Alianza Ed., vol. 6, pp. 549-643.

AlCOCK, Pete (1993): Understanding Poverty, Londres, MacMillan.

ANISI, David (1995): Creadores de escasez. Del bienestar al miedo, Madrid, Alianza Editorial.

AsHFord, Douglas E. (1986): The Emergence of the Welfare State, Oxford, Basil Blackwell.

Avinieri, S., y Shaplit, A. de (comps.) (1992): Communitarism and Individualism, OxfordNueva York, Oxford Univ. Press.

Badelt, Christoph (1984): «New Concepts for the Supply of Government Services», en Horst Hanusch (ed.), Public Finance and the Quest for Efficiency, Detroit, Wayne State University Press, pp. 267-278.

Barry, Brian, y GoOdin, Robert E. (1992): Free Movement, Harvester.

BARRY, Norman (1990): Welfare, Londres, Open University Press.

BriggS, A. (1961): «The Welfare State in historical perspective», European Journal of Sociology, 2: 221-258.

BRITTAN, Samuel (1983): The Role and Limits of Government: Essays in Political Economy, Londres, Temple Smith.

BRYSON, L., et alii (eds.) (1956): Aspects of Human Equality, Nueva York, Harper.

BUCHANAN, James (1978): The Economics of Politics, Londres, IEA.

Buchanan, James, y Tullock, G. (1965): The Calculus of Consent, Ann Arbor, University of Michigan Press.

Casilda, Ramón, y Tortosa, J. M. (comps.) (1996): Pros y Contras del Estado de Bienestar, Madrid, Tecnos.

Clarke, J.; Cochrane, A., y Smart, C. (1987): Ideologies of Welfare, Londres, Routledge \& Kegan Paul.

Donati, P. P. (comp.) (1985): Le Frontiere della Politica Sociale, Milán, Franco Angeli.

Downs, Anthony (1957): An Economic Theory of Democracy, Nueva York, Harper.

FlORA, Peter (1981): «Solution or Source of Crisis? The Welfare State in Historical Perspective», en W. J. Mommsen (ed.), The Emergence of the Welfare State in Britain and Germany, Londres, Croom-Helm, pp. 343-383.

Fraser, Nancy (1987): "Women, welfare and the politics of need interpretation», Thesis Eleven, vol. 17.

García Pelayo, Manuel (1981): Las transformaciones del Estado contemporáneo, Madrid, Alianza Editorial.

Giddens, Anthony (1994): Beyond Left and Right. The Future of Radical Politics, Londres, Polity Press.

Goldschmidt-Clermont, L. (1982): Unpaid Work in the Household, Génova, International Labour Office, Women Work and Development.

Goodin, R. E., y Legrand, J. (eds.) (1987): Not Only the Poor: The Middle Classes and the Welfare State, Londres, Allen \& Unwin.

Gough, Ian (1979): The Political Economy of the Welfare State, Londres, MacMillan.

Gray, John (1993): Post-Liberalism. Studies in Political Thought, Londres, Routledge \& Kegan Paul.

Habermas, Jürgen (1981): Historia y Crítica de la Opinión Pública, Madrid, Gustavo Gili.

Handler, Joel F. (1995): The Poverty of Welfare Reform, New Haven, Yale University Press.

HaYeK, F. A. (1976): Law, Legislation and Liberty, 3 vols., Londres, Routledge \& Kegan Paul.

- (1993): The Fatal Conceit, Londres, Routledge \& Kegan Paul.

Johnson, Norman (1990): Reconstructing the Welfare State. A Decade of Change 1980-1990, Harvester.

JudGE, K. (1987): «The British Welfare State in transition», en R. R. Friedman, N. Gilbert y M. Scheter (eds.), Modern Welfare States, Nueva York, New York University Press.

Kramer, Ralph M. (1981): Voluntary Agencies in the Welfare State, Berkeley, University of California Press. 
Marshall, T. H. (1963): Class, Citizenship and Social Development, Londres, Allen \& Unwin.

- (1981): The Right to Welfare and Other Essays, Londres, Heinemann.

Mishra, Ramesh (1990): The Welfare State in Capitalist Society: policies of retrenchment and maintenance in Europe, North America and Australia, Harvester Wheatshea F.

Montoro, Ricardo (1985): "Crisis de legitimación y crisis económica en el Estado Social de Bienestar", Revista de Estudios Políticos, 48: 177-196.

- (1987): «Neoconservadurismo y crisis del Estado de Bienestar», en VV.AA., Política y Sociedad (Libro homenaje al Profesor Francisco Murillo Ferrol), Madrid, Centro de Investigaciones Sociológicas/Centro de Estudios Constitucionales, pp. 269-283.

Montoro, Cristóbal, y Montoro, Ricardo (1996): «Del Estado de Bienestar a la Sociedad del Bienestar», en R. CAsilda y J. M. Tortosa (comps.), Pros y Contras del Estado del Bienestar, Madrid, Tecnos, pp. 61-82.

MORLEY, Felix (ed.) (1977): Essays on Individuality, Indianapolis, Liberty Press.

Murray, Charles (1988): Small Government and the Pursuit of Happiness, Nueva York, Basic Books.

NisBeT, Robert (1991): Conservatism, Londres, Open University Press.

OfFe, Claus (1984): Contradictions of the Welfare State, Londres, Hutchinson.

Oppenheim, Felix (1981): Political Concepts: A Reconstruction, Chicago, University of Chicago Press.

Pakulski, Jan, y Waters, Malcolm (1996): The Death of Class, Londres, Sage Publications.

PEACOCK, Alan, y Wiseman, Jack (1961): The Growth of Public Expenditure in the United Kingdom, Oxford, Oxford University Press.

PEACOCK, Alan (1982): "On the Anatomy of Collective Failure», Festschrift für Paul Senf, Public Finance, 33-43.

Pennock, J. R., y Chapman, J. W. (eds.) (1967): Equality, Nueva York, Atherton.

Pérez OrTiZ, Lourdes (1995): Vejez y Sociedad, Universidad Autónoma de Madrid, Tesis Doctoral, multicopiado.

- (1996): "Las limitaciones del sistema de pensiones», en R. Casilda y J. M. Tortosa (comps.), Pros y Contras del Estado del Bienestar, Madrid, Tecnos, pp. 154-176.

PINKER, R. (1979): The Idea of Welfare, Londres, Heinemann.

RAE, Douglas, et alii (1981): Equalities, Cambridge, Harvard University Press.

RAWLS, John (1971): Theory of Justice, Harvard, Harvard University Press.

REES, J. (1971): Equality, Nueva York, Praeger.

Rein, Martin, y Rainwater, L. (eds.) (1986): Public/Private Interplay in Social Protection, Nueva York, M. E. Sharpe, Armonk.

Rose, Richard (1984): Understanding Big Government, Londres y Beverly Hills, Sage Pub.

Rose, R., y Shiratori, R. (eds.) (1986): The Welfare State East and West, Oxford, Oxford University Press.

SARTORI, Giovanni (1992): Elementos de teoría política, Madrid, Alianza Ed.

- (1993): La Democracia después del Comunismo, Madrid, Alianza Ed.

SCRUTON, Roger (1980): The Meaning of Conservatism, Harmondsworth, Penguin.

SCHOECK, Helmut (1977): «Individuality vs. Equality», en Felix Morley (ed.), Essays on Individuality, Indianapolis, Liberty Press, pp. 145-176.

SELDON, Arthur (1994): Capitalismo, Madrid, Unión Editorial.

Smith, B. L. R., y Rosenbaum, Nelson M. (1981): The Fiscal Capacity of the Voluntary Sector, Washington, D.C., The Brookings Institution.

Sowell, T. (1981): Markets and Minorities, Nueva York, Basic Books.

Sugden, R. (1984): Who Cares?, Londres, Institute of Economic Affairs.

Swann, Abraham de (1988): In Care of the State, Cambridge, Polity Press.

TAWNEY, R. H. (1931): Equality, Londres, Allen \& Unwin.

TAYlor-Gooby, P. (1984): Social Theory and Social Welfare, Londres, Allen \& Unwin.

TESTER, Keith (1992): Civil Society, Londres, Routledge.

Thompson, Dennis L. (ed.) (1983): «Policy toward Public-Private Relations: A Symposium», Policy Studies Journal, 11: 3. 
Titmuss, Richard M. (1958): Essays on the Welfare State, Londres, Allen \& Unwin.

- (1968): Commitment to Welfare, Londres, Allen \& Unwin.

Tullock, G. (1985): The Economics of Wealth and Poverty, Brighton, Wheatsheaf.

Vallespín, Fernando, y García-Guitián, Elena (1995): «El neoliberalismo (1): Friedrich Hayek, Raymond Aron, Isaiah Berlin», en Fernando Vallespín (ed.), Historia de la Teoría Política, Madrid, Alianza Ed., vol. 6, pp. 15-87.

Weisbrod, Burton A. (1977): The Voluntary Non-Profit Sector, Lexington, Heath.

WeST, Edwin G. (1994): La Educación y el Estado, Madrid, Unión Editorial.

White, Michelle J. (ed.) (1981): Non-Profit Firms in a Three-Sector Economy, Washington, Urban Institute Press.

Wolf, Charles (1979): "A Theory of Non-Market Failure», Journal of Law and Economics, 22: 107-139.

\begin{abstract}
Based on the crisis of the welfare state and drawing on the hypotheses defended by advocates of the welfare mix, this paper examines the rights and duties of the welfare state, the need to link social policy with economic policy, the limits between privacy and publicity, and the close connexion between individual welfare and public welfare. In this framework, the author makes suggestions for reforming the welfare state with a view to steering it towards a welfare society by recovering the individualist principle and redefining equality of opportunities in a scenario in which state, market and families pool their efforts in a bid to achieve social and individual welfare in a new historical period, one that comes directly in the wake of the welfare state.
\end{abstract}

